\title{
Influence of hCG injection and steroid treatment on prostaglandin metabolism by rabbit uterus and oviduct
}

\author{
R. R. Bodkhe $\dagger$ and M. J. K. Harper \\ Center for Research and Training in Reproductive Biology, \\ Department of Obstetrics and Gynecology, The University of Texas Health Science Center at \\ San Antonio, 7703 Floyd Curl Drive, San Antonio, Texas 78284, U.S.A.
}

\begin{abstract}
Summary. Metabolism of PGE-2 and PGF-2 $\alpha$ by cytosolic fractions (100000 $\mathrm{g}$ supernatant) of rabbit uterus, oviduct and lung was measured in vitro. Metabolism of PGE-2 was greater than that of PGF-2 $\alpha$ for oviduct and uterus. After an ovulating injection of hCG metabolism of both PGE-2 and PGF- $2 \alpha$ by lung and uterus declined linearly up to $72 \mathrm{~h}$ (during the time of ovum transport). The amount of PG metabolism by the oviduct did not change significantly during this period, but the percentage changes of PGE-2 and PGF- $2 \alpha$ metabolism from oestrous values did differ, and perhaps indicated a change in the ratio of intracellular PGs. No change of metabolism of either PG by lung, uterus or oviduct occurred at 24 or $72 \mathrm{~h}$ after an injection of $250 \mu \mathrm{g}$ oestradiol cyclopentylpropionate given concomitantly with the hCG (a treatment regimen which causes 'tube-locking' of ova). However, progesterone treatment, in a regimen known to cause accelerated transport of ova through the oviduct, caused significantly enhanced metabolism of both PGE-2 and PGF- $2 \alpha$ by uterus and oviduct, but not lung, 30 and $48 \mathrm{~h}$ later except for PGE- 2 by uterus at $30 \mathrm{~h}$. These results suggest that changes in metabolism of PGE-2 and PGF$2 \alpha$ by the oviduct may be involved in the mechanisms controlling ovum transport.
\end{abstract}

\section{Introduction}

We have demonstrated that exogenous prostaglandins (PG) E and F have characteristic effects on rabbit oviductal motility in vivo (Spilman \& Harper, 1973, 1974, 1975). PGE-1 and PGE-2 suppress spontaneous motility, while PGF-1 $\alpha$ and PGF-2 $\alpha$ stimulate activity. These studies and those of Ingelman-Sundberg, Sandberg, Rydén \& Molfese (1971) and Horton, Main \& Marley (1965) suggest that PGs might be intimately involved in the physiological control of ovum transport. Recent experiments with endotoxin which produced elevated levels of PGEs and PGFs in uterine vein blood of rabbits, and associated accelerated ovum transport, further implicate the importance of the balance between PGs in control of ovum transport (Harper, Valenzuela \& Hodgson, 1978; Hodgson, Harper \& Valenzuela, 1978).

PGs are not stored intracellularly (Bito, 1975; Samuelsson, Granstrom, Gréen, Hamberg \& Hammarström, 1975) and thus tissue concentrations cannot be easily correlated with cellular production. Plasma levels of PGs draining the organ of primary interest are more informative but still afford no direct evidence as to the exact site of steroid action in changing PG levels. There are various ways in which this might occur: an action on substrate availability, on the PG synthetase system, on the availability of enzyme co-factors or on the PG metabolizing enzymes - the 15-hydroxyprostaglandin dehydrogenase and $\Delta^{13}$-prostaglandin reductase.

* Reprint requests to Dr M. J. K. Harper.

$\dagger$ Present address: Department of Biochemistry, Government Medical College, Jabalpur, M.P., India. 
Ham, Cirillo, Zanetti \& Kuehl (1975) reported that oestrogen did not change total PG production in incubations of uterine homogenates from oestrogen-treated castrated rats. Total production of PGF- $2 \alpha$ and PGE-2 by oviducts of castrated, oestrous and oestrogen-treated rabbits did not differ significantly (Valenzuela \& Harper, 1976). Furthermore, PG biosynthesis by kidney was unaffected by treatment with cycloheximide which inhibited protein synthesis by 63.7\% (Blackwell, Flower, Parsons \& Vane, 1975a). By contrast, Zor, Strulovici, Nimrod \& Lindner (1977) inhibited PGE production from rat Graafian follicles in vitro with both actinomycin $D$ and cycloheximide. Hormones can more easily affect the 15-hydroxyprostaglandin dehydrogenase system. Progesterone has been shown to increase the activity of 15hydroxyprostaglandin dehydrogenase in rat myometrium and deciduoma (Alam, Russell, Tabor \& Moulton, 1976) and in the lungs of pregnant rats (Blackwell \& Flower, 1976) and pregnant and progesterone-treated rabbits (Sun \& Armour, 1974; Bedwani \& Marley, 1975); oestradiol, by contrast, decreases the activity in kidneys of adrenalectomized rats (Blackwell \& Flower, 1976). Blackwell, Flower \& Vane (1975b) have shown that 15-hydroxyprostaglandin dehydrogenase is a short-lived enzyme in the cell whose replacement depends upon de-novo protein, but not RNA, synthesis. A decrease in cellular protein synthesis may therefore decrease 15-hydroxyprostaglandin dehydrogenase activity and by implication result in cells being exposed to higher PG levels.

The present study was undertaken to examine metabolism of PGE-2 and PGE-2 $\alpha$ during ovum transport in the rabbit oviduct and uterus.

\section{Materials and Methods}

\section{Animals}

Mature female New Zealand White rabbits weighing $3 \cdot 0-4.5 \mathrm{~kg}$ and over 6 months old were caged individually in a controlled environment with a photoperiod of $14 \mathrm{~h}$ light $/ 24 \mathrm{~h}$. Water and food were supplied ad libitum. Pseudopregnancy was induced by the intravenous administration of 100 i.u. hCG (APL: Ayerst, New York) 1 month before use to ensure a good development of the reproductive tract.

A second injection of 100 i.u. hCG was given to each animal at time zero. Groups of animals were then killed 24, 30, 48 and $72 \mathrm{~h}$ later by an overdose of sodium pentobarbital (Diabutal: Diamond Labs, Des Moines, Iowa). A group of oestrous animals was also studied. In addition, 2 groups of rabbits received $250 \mu \mathrm{g}$ oestradiol cyclopentylpropionate subcutaneously (s.c.) in oil (Upjohn Co., Kalamazoo, Michigan) with the hCG at time zero, and were then killed 24 or $72 \mathrm{~h}$ later. Two other groups received $2.5 \mathrm{mg}$ progesterone s.c. in oil daily for 3 days before $\mathrm{hCG}$, the final injection being given at the same time as the hCG. These rabbits were killed 30 or $48 \mathrm{~h}$ after hCG.

\section{Chemicals}

$\left[5,6,8,11,12,14,15-{ }^{3} \mathrm{H}(\mathrm{N})\right]$ Prostaglandin $\quad$ E-2 $\quad$ (sp. act. $117 \quad \mathrm{Ci} / \mathrm{mmol}$ ) and $\left[5,6,8,9,11,12,14,15-{ }^{3} \mathrm{H}(\mathrm{N})\right]$ prostaglandin $\mathrm{F}-2 \alpha$ (sp. act. $178 \mathrm{Ci} / \mathrm{mmol}$ ) were purchased from Amersham Corp. (Arlington Heights, Illinois). Prostaglandin standards were the generous gift of Dr J. E. Pike (Upjohn Co., Kalamazoo, Michigan). $\beta$-Nicotinamide adenine dinucleotide $\left(\mathrm{NAD}^{+}\right.$) was obtained from Sigma Chemical Co. (St. Louis, Missouri). All the chemicals were reagent grade and used as purchased except that the ethyl acetate and methanol were redistilled before use and the ethanol was 200 proof (Rossville Gold Shield) (IMC Chemical Group Inc., Terre Haute, Indiana).

\section{Preparation of enzyme fraction}

Tissues (oviducts, uteri and lungs) were removed as rapidly as possible from rabbits after killing with an overdose of sodium pentobarbital and immediately placed in ice cold 44 mM-Tris- 
$\mathrm{HCl}$ buffer ( $\mathrm{pH} 8$ ) containing $1 \mathrm{~mm}$-EDTA. Lung and uterine tissue from individual animals was used, but the oviducts from 2 rabbits had to be pooled to provide adequate cytosol for incubation. This accounts for the fewer observations and the lower concentration of protein with oviductal tissue. The tissues were trimmed of extraneous fat, blotted and weighed, and homogenized in 4 volumes of Tris buffer with a Polytron homogenizer (Kinematica GMBH, Lucerne, Switzerland) 5 times for $10 \mathrm{sec}$ at top speed followed by 1 -min intervals on ice and then subjected to further homogenization with a Teflon pestle 3 times for $1 \mathrm{~min}$. These procedures were carried out in a cold room. The homogenate was then filtered through 4 layers of sterile gauze and the filtrate centrifuged at $100000 \mathrm{~g}$ at $5^{\circ} \mathrm{C}$ for $1 \mathrm{~h}$. The resultant pellet was discarded and the supernatant containing 15-hydroxyprostaglandin dehydrogenase (EC 1.1.1.141) and $\Delta^{13}$-prostaglandin reductase was used immediately or stored under liquid nitrogen overnight if all studies could not be completed on the same day. Protein was measured in an aliquot of the supernatant by the method of Lowry, Rosebrough, Farr \& Randall (1951) with bovine serum albumin as standard.

\section{Incubation procedures and assay for metabolism}

In preliminary experiments the substrate concentration, cofactor concentration, time and protein concentration useful under our assay conditions was determined. For all these experiments uterine cytosolic fractions prepared from oestrous rabbits were used. The final incubation conditions were as follows: a $1 \mathrm{ml}$ aliquot of the enzyme preparation in Tris- $\mathrm{HCl}$ buffer containing various concentrations of protein, depending on the tissue, was incubated in a Dubnoff metabolic shaker at $37^{\circ} \mathrm{C}$ for $60 \mathrm{~min}$ to study PGF-2 $\alpha$ dehydrogenase and for $30 \mathrm{~min}$ to study PGE-2 dehydrogenase. The incubation mixture contained $2 \mathrm{mM}-\mathrm{NAD}^{+}, 1 \mu \mathrm{g}$ of the appropriate unlabelled PG and about 40000 c.p.m. of the appropriate labelled PG (representing approximately $126 \mathrm{pg}$ PGE-2 and $85 \mathrm{pg}$ PGF-2 $\alpha$ ). At the end of the incubation, the reaction was stopped by dipping the tubes in ice and adding $1.0 \mathrm{ml}$ acetate buffer $(\mathrm{pH} 4.5)$. The unreacted PGs and their metabolites were extracted by mixing vigorously for $2 \mathrm{~min}$ with $4 \mathrm{ml}$ ethyl acetate. The extract was evaporated to dryness under nitrogen gas and the residue redissolved in $1.0 \mathrm{ml}$ ethanol. Procedural losses were determined in a $0.1 \mathrm{ml}$ aliquot and the average efficiency was $41 \%$ for ${ }^{3} \mathrm{H}$. Recovery of the labelled PGs when allowance was made for the loss of one tritium atom during metabolism was greater than $90 \%$ before chromatography.

To the remainder of the extract in ethanol was added $50 \mu \mathrm{l}$ ethanol containing $10 \mu \mathrm{g}$ authentic PG (F-2 $\alpha$ or E-2 as appropriate) and its corresponding 15-keto and 13,14-dihydro-15keto metabolites. The mixture was vortexed vigorously and again evaporated under nitrogen gas. The residue was then redissolved in $50 \mu \mathrm{l}$ chloroform and spotted quantitatively onto plasticbacked thin-layer chromatographic plates covered with activated and pre-soaked silica gel (Eastman-Kodak, No. 13181, Rochester, New York). The standards were spotted on the plates separately as reference markers. The plates were developed to a distance of $15 \mathrm{~cm}$ in chloroform : methanol: glacial acetic acid (90:5:5 by vol.) (Sun \& Armour, 1974) and then dried. The average $R_{\mathrm{F}}$ values obtained with this system are as follows: PGE-2, 0.31; 15-keto PGE-2, 0.50; 13,14-dihydro-15-keto-PGE-2, 0.52; PGF-2a, 0.16; 15-keto PGF-2 $\alpha, 0.32$; 13,14-dihydro-15keto-PGF-2 $\alpha, 0.48$. The zones corresponding to the authentic markers were visualized by brief exposure to iodine vapour (Blackwell et al., 1975b) and then also scanned with a Radiochromatogram scanner (Packard model No. 7201). The relevant zones from the plates were cut out for quantitative determination of radioactivity by liquid scintillation counting. Boiled cytosol was always included in each series of incubations as a control for non-enzymic conversion. The results were corrected for procedural losses, non-enzymic conversion and loss of one tritium atom during metabolism and then calculated as $\mathrm{pmol} / \mathrm{mg}$ cytosolic protein. The actual percentage of $\mathrm{PG}$ oxidized $/ \mathrm{mg}$ protein or of product formed $/ \mathrm{mg}$ protein was determined by the formula $(\mathrm{pmol} \times \mathrm{mol} . \mathrm{wt} / \mathrm{pg}$ substrate $) \times 100$. The pg substrate was $1 \times 10^{6}$ unlabelled PG, 
because the pg labelled PG could be disregarded for practical purposes. Statistical comparisons were effected by analysis of variance, followed by a Student-Newman-Kuels test (Sokal \& Rohlf, 1969) or linear regression (Texas Instruments Statistics Library Program ST 1-08).

\section{Results}

The results of preliminary experiments to determine optimal incubation conditions for cytosolic preparations from oestrous rabbits are shown in Text-figs $1-4$. When up to $8 \mu \mathrm{g}$ unlabelled PG was used, metabolism was linear up to $1 \mu \mathrm{g}$ PG and then reached a plateau at $2 \mu \mathrm{g}$ (Text-fig. 1).
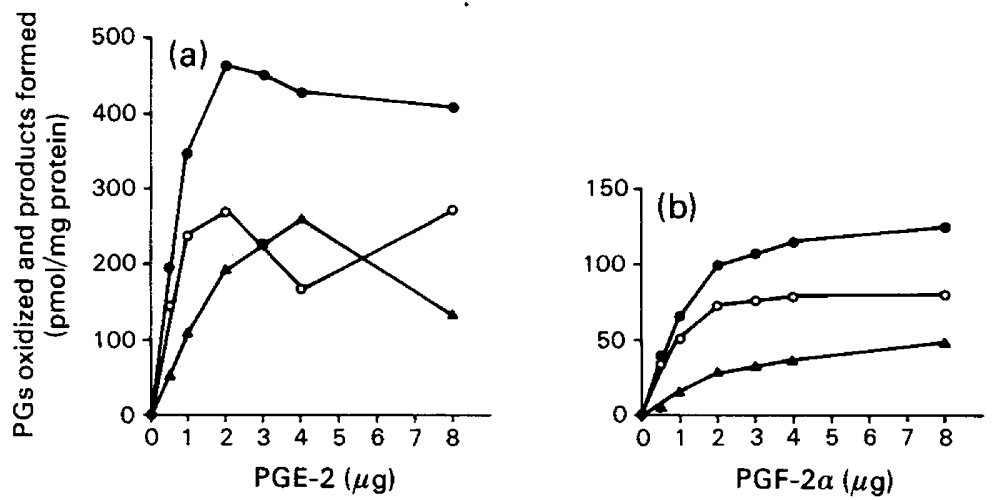

Text-fig. 1. PGs oxidized $(O)$ and 15-keto $(\Delta)$ and 13,14-dihydro-15-keto $(O)$ metabolites formed in relation to various concentrations of substrate, PGE-2 (a) and PGF-2 $\alpha$ (b). The incubation mixtures contained unlabelled PG, 40000 c.p.m. $\left[{ }^{3} \mathrm{H}\right] \mathrm{PG}, 2$ mM-NAD ${ }^{+}$and 45.45 (a) and 4.8-5.8 (b) $\mathrm{mg}$ uterine cytosolic protein $/ \mathrm{ml}$. The incubation time was $30 \mathrm{~min}$ (a) and $60 \mathrm{~min}(\mathrm{~b})$ at $\mathrm{pH} 8.0$. Each point is the mean of 3 experiments.

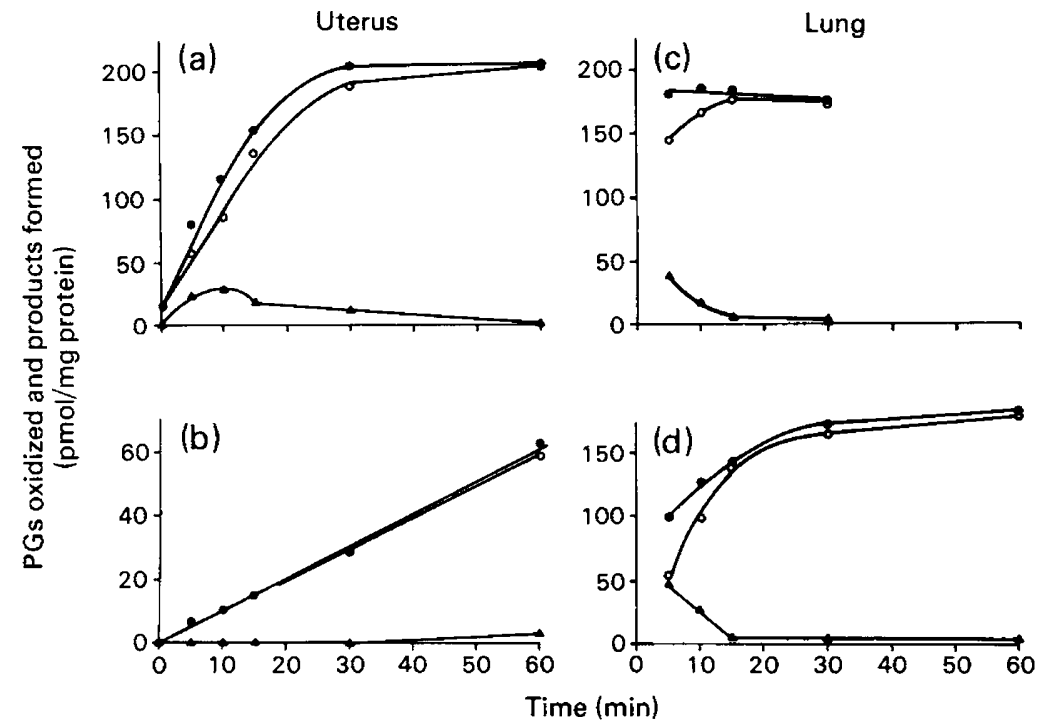

Text-fig. 2. PGE-2 (a, c) and PGF-2 $\alpha$ (b, d) oxidized (O) and 15-keto (A) and 13,14-dihydro15-keto (O) metabolites formed in relation to time of incubation. The incubation mixtures contained (a, b) uterine cytosol $10 \cdot 1 \mathrm{mg}$ protein $/ \mathrm{ml}, \sim 40000$ c.p.m. $\left[{ }^{3} \mathrm{H}\right] \mathrm{PG}, 1 \mu \mathrm{g}$ unlabelled PG and $2 \mathrm{mM}-\mathrm{NAD}^{+}$at $\mathrm{pH} 8.0$, and (c, d) lung cytosol $12.5 \mathrm{mg}$ protein $/ \mathrm{ml}, \sim 40000$ c.p.m. $\left[{ }^{3} \mathrm{H}\right] \mathrm{PG}, 1 \mu \mathrm{g}$ unlabelled $\mathrm{PG}$ and $2 \mathrm{mM}^{-\mathrm{NAD}}{ }^{+}$at $\mathrm{pH} 8.0$. Each point is the mean of duplicate values from 1 experiment. 
For subsequent experiments, $1 \mu \mathrm{g}$ PGE-2 or PGF-2 $\alpha$ tromethamine salt (calculated as base) was used. As shown in Text-fig. 2, when uterine cytosol was used maximal oxidation of PGE-2 occurred by $30 \mathrm{~min}$ and was linear up to that time, but oxidation of PGF-2 $\alpha$ was linear up to 60 min. With lung cytosol, maximal oxidation of PGE- 2 had occurred by $5 \mathrm{~min}$, the earliest time studied, and that of PGE-2 $\alpha$ by $30 \mathrm{~min}$, although more than $50 \%$ had been metabolized within 5 min. Because of the slow rate of metabolism of PGs by reproductive tissue, subsequent incubations were for $30 \mathrm{~min}$ when PGE-2 was the substrate and $60 \mathrm{~min}$ when PGF-2 $\alpha$ was the substrate. Metabolism of PGE-2 and PGF- $2 \alpha$ by different concentrations of uterine cytosol was linear over the range studied (Text-fig. 3). In subsequent experiments the range of protein concentrations $(\mathrm{mg} / \mathrm{ml})$ was $3.8-9.0$ for oviduct, $4 \cdot 1-14.0$ for uterus and $10.1-18.4$ for lung. Variation in concentration was caused by different weights of reproductive tracts and a standard dilution procedure. In all these experiments, 2 mM-NAD ${ }^{+}$was used as co-factor. Additional experiments showed that these PG metabolizing enzymes were relatively insensitive to the concentration of co-factor, similar results being obtained with $1-4 \mathrm{mM}-\mathrm{NAD}^{+}$, although there was some suggestion that increasing concentrations were inhibiting oxidation of PGF-2 $\alpha$. Formation of 13,14-dihydro-15-keto PGE-2 and PGF-2 $\alpha$ was enhanced at the expense of the

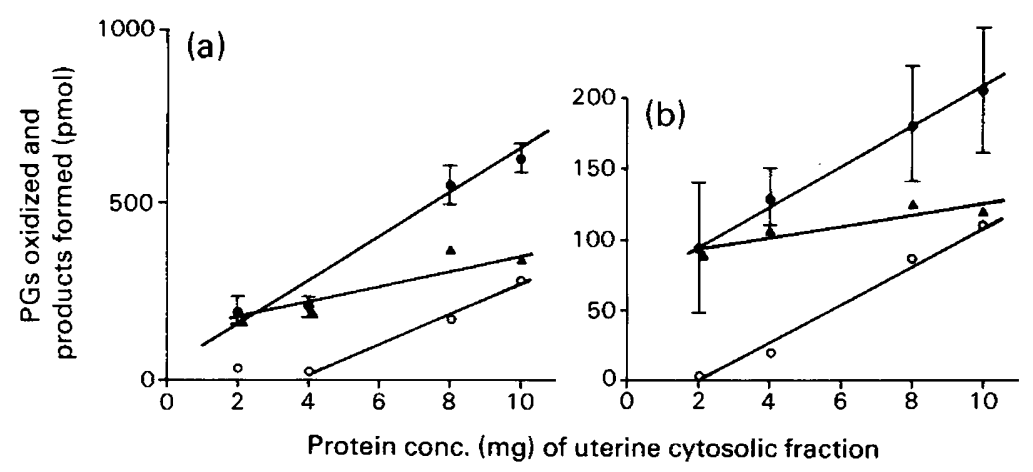

Text-fig. 3. PGS oxidized $(O)$ and 15-keto $(\Delta)$ and 13,14-dihydro-15-keto $(0)$ metabolites formed (a, PGE-2; b, PGF-2 $\alpha$ ) in relation to amount of uterine cytosolic protein added to the incubation mixture, which also contained $1 \mu \mathrm{g}$ unlabelled PG, $\sim 40000$ c.p.m. $\left[{ }^{3} \mathrm{H}\right] \mathrm{PG}$ and 2 mM-NAD ${ }^{+}$. The incubation times were $30 \mathrm{~min}(\mathrm{a})$ and $60 \mathrm{~min}(\mathrm{~b})$ at $\mathrm{pH} 8.0$. Each point is the mean of 2 experiments.
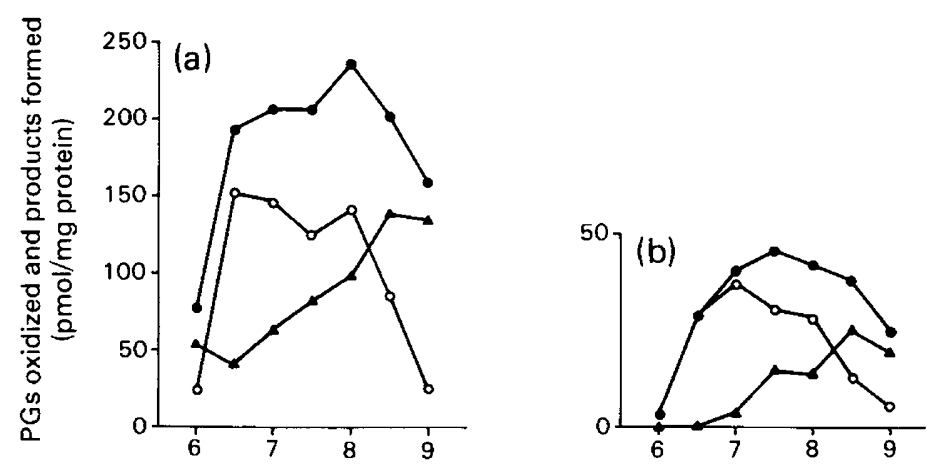

$\mathrm{pH}$

Text-fig. 4. PGs oxidized $(O)$ and 15-keto $(\Delta)$ and 13,14-dihydro-15-keto $(O)$ metabolites formed (a, PGE-2; b, PGF-2 $\alpha$ ) in relation to $\mathrm{pH}$ of incubation. The incubation mixture contained uterine cytosol $8.5 \mathrm{mg}$ protein $/ \mathrm{ml}, \sim 40000$ c.p.m. $\left[{ }^{3} \mathrm{H}\right] \mathrm{PG}, 1 \mu \mathrm{g}$ unlabelled PG and $2 \mathrm{~mm}-$ $\mathrm{NAD}^{+}$. The incubation times were $30 \mathrm{~min}(\mathrm{a})$ and $60 \mathrm{~min}(\mathrm{~b})$ at $\mathrm{pH} 8.0$. There was a separate control for each $\mathrm{pH}$ value. Each point is the mean of duplicate values from 1 experiment. 
15-keto metabolites when the $\mathrm{NAD}^{+}$concentration was increased from 0.4 to $1 \mathrm{mM}$. A concentration of $2 \mathrm{mM}$ was used in all other experiments. The data for different $\mathrm{pH}$ values are shown in Text-fig. 4. The $\mathrm{pH}$ optimum for maximal metabolism of the primary PGs was 8.0 but that for 15-hydroxyprostaglandin dehydrogenase was 8.5 and for $\Delta^{13}$-prostaglandin reductase $7 \cdot 0$. In all subsequent experiments $\mathrm{pH} 8 \cdot 0$ was used.

\section{Effect of injection of $h C G$}

The effect of time elapsing after an injection of 100 i.u. hCG on the metabolism of PGE-2 and PGF-2 $\alpha$ was investigated (Table 1). Lung from oestrous rabbits metabolized both PGE-2 and PGF- $2 \alpha$ equally during the time of incubation, although oxidation of both PGs decreased significantly with time. By contrast, the uterus and oviduct of oestrous animals metabolized about 10 times more PGE-2 than PGF-2 $\alpha$ in the same time. By Student-Newman-Kuels test there were no significant differences between different time groups for metabolism of either PGE2 or PGF- $2 \alpha$ by oviduct. However, uterine metabolism of PGE- 2 was significantly depressed by $48 \mathrm{~h}$, and of PGF- $2 \alpha$ by $24 \mathrm{~h}$ after hCG.

These data were subjected to linear regression analyses, and the results are shown in Table 2. Metabolism of PGE-2 and PGF-2 $\alpha$ by lung declined significantly with time after hCG injection, and the slopes of the regressions were very similar. Metabolism of PGE-2 and PGF-2 $\alpha$ by uterus also declined significantly with time after hCG but in this case the slope of the regression for metabolism of PGE-2 was steeper and more variable than that for PGF- $2 \alpha$. Metabolism of both PGs by the oviduct did not show a linear decline with time up to $72 \mathrm{~h}$ after hCG injection. If, however, these data are expressed as percentage changes from oestrous values, with lung and uterus the decreases in metabolism of PGE-2 and PGF-2 $\alpha$ parallel each other very closely but this is not so for the oviduct. Metabolism of PGE-2 in oviduct is increased at all times after hCG, being greatest at 24,30 and $72 \mathrm{~h}$. By contrast, metabolism of PGF- $2 \alpha$ is decreased at all times, being reduced most at $48 \mathrm{~h}$ after hCG. This may indicate a significant change in the balance of intracellular PG levels at about the time ova start to move into the uterus.

The amounts of products formed are also shown in Table 1. Owing to the longer period of incubation for lung tissue (well beyond the time for maximal metabolism of the substrates) almost all the products were found as the 13,14-dihydro-15-keto metabolites. There was a similar trend of a decrease with time following hCG injection, but this was only significant for the 13,14-dihydro-15-keto PGE-2 and PGF-2 $\alpha$ at the 24, 48 and $72 \mathrm{~h}$ times (Table 1). The formation of 15-keto metabolites after incubation of uterine cytosol declined, and was significantly less than that in oestrous animals at all times studied for PGE-2 but not for that for PGF-2 $\alpha$. Formation of the 13,14-dihydro-15-keto metabolites after uterine incubation did not change with time for PGE-2, but were lower at 48 and $72 \mathrm{~h}$ for PGF-2 $\alpha$. After incubation of oviductal cytosol, formation of both metabolites from PGE-2 and PGF- $2 \alpha$ was unaffected by time after hCG injection, with the exception that formation of 13,14-dihydro-15-keto PGF- $2 \alpha$ was decreased at $72 \mathrm{~h}$, thus causing a significant accumulation of the 15 -keto metabolite.

\section{Effect of hormonal treatment}

Treatment of rabbits with a dose of oestrogen was without significant effect on metabolism of PGs (Table 3). Compared to oestrous values there was an oestrogen-induced change in the oviduct from decreased metabolism of PGF- $2 \alpha$ to increased metabolism $(-15$ to $+16 \%$ and -21 to $+32 \%$ at 24 and $72 \mathrm{~h}$ respectively), while metabolism of PGE-2 was more greatly increased at both times $(+36$ to $+61 \%$ and +47 to $+72 \%$ respectively). There were no significant changes in the products formed in lung tissue. In the uterus, more of the 13,14dihydro-15-keto PGE-2 metabolite was formed at $24 \mathrm{~h}$, and of the 15-keto PGE-2 metabolite at $72 \mathrm{~h}$. In the oviduct, more 13,14-dihydro-15-keto PGF-2a was formed $72 \mathrm{~h}$ after the oestrogen 


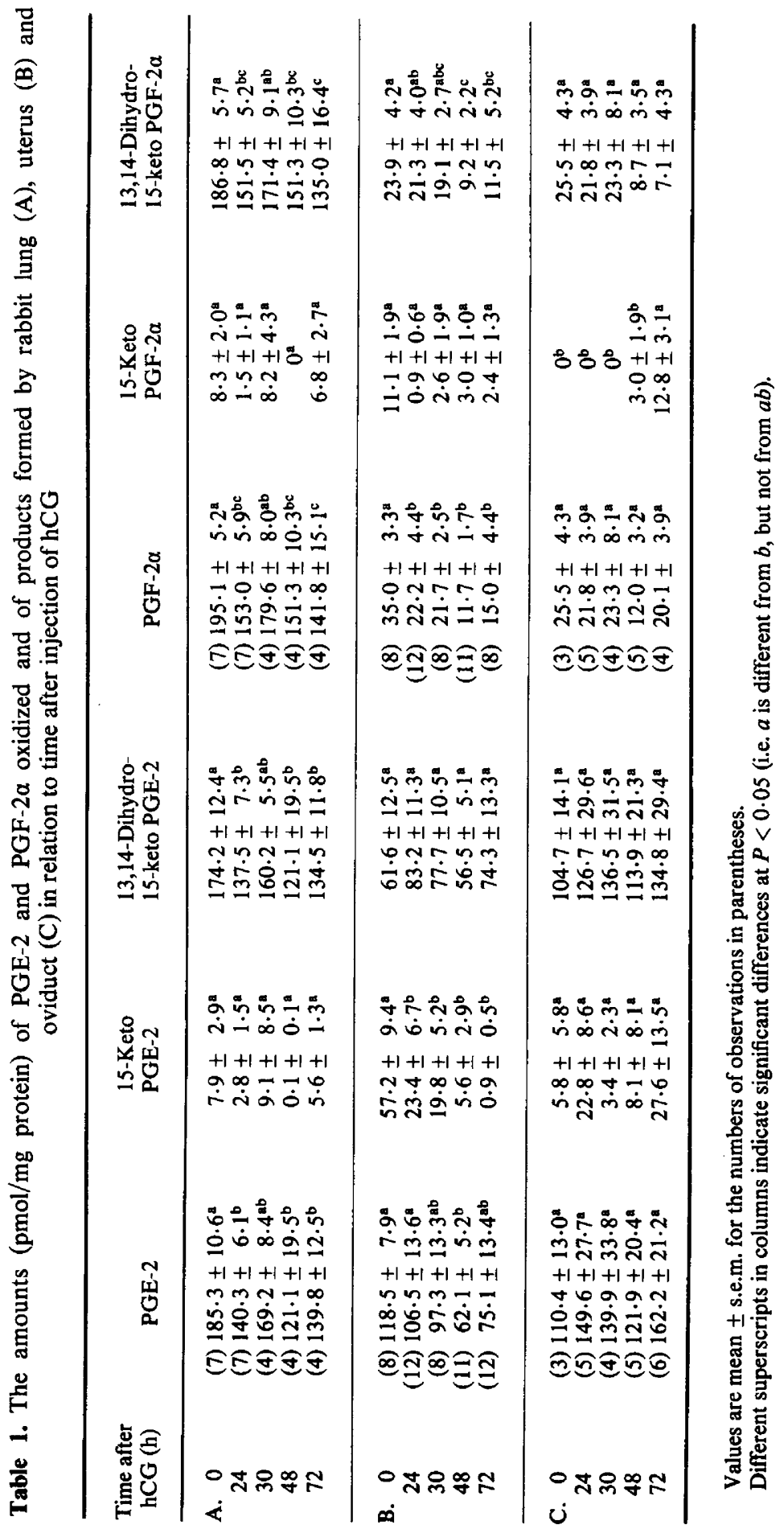




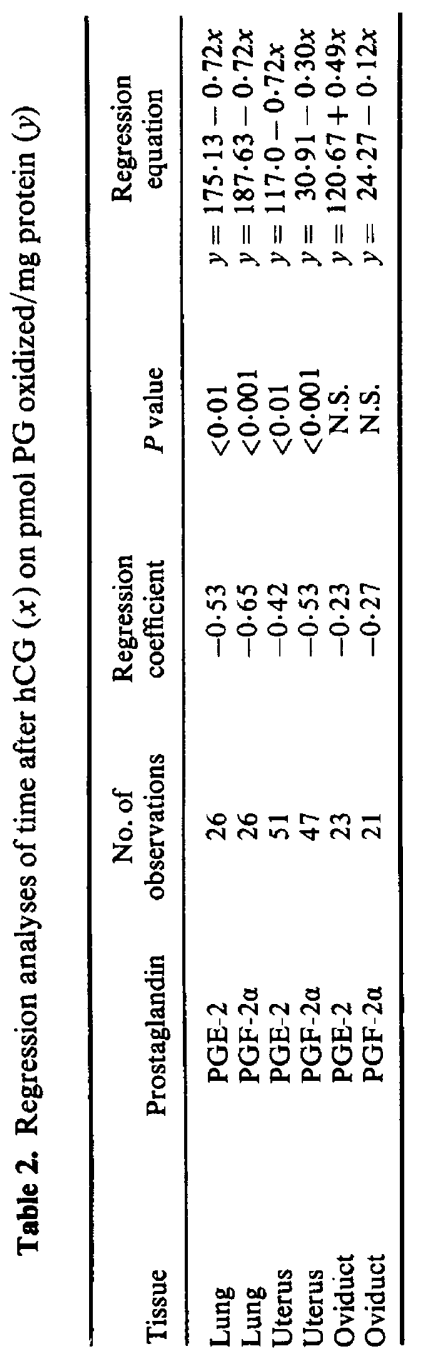

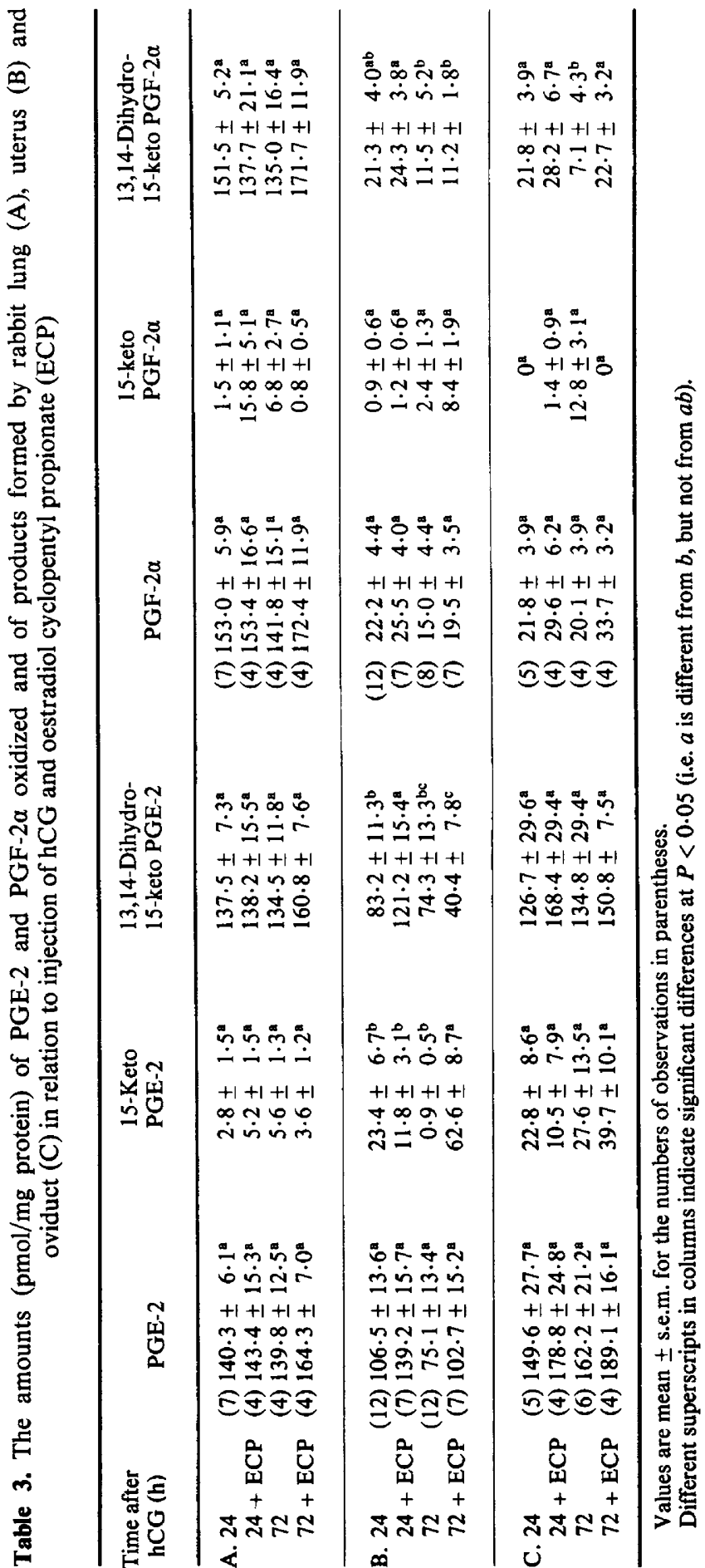




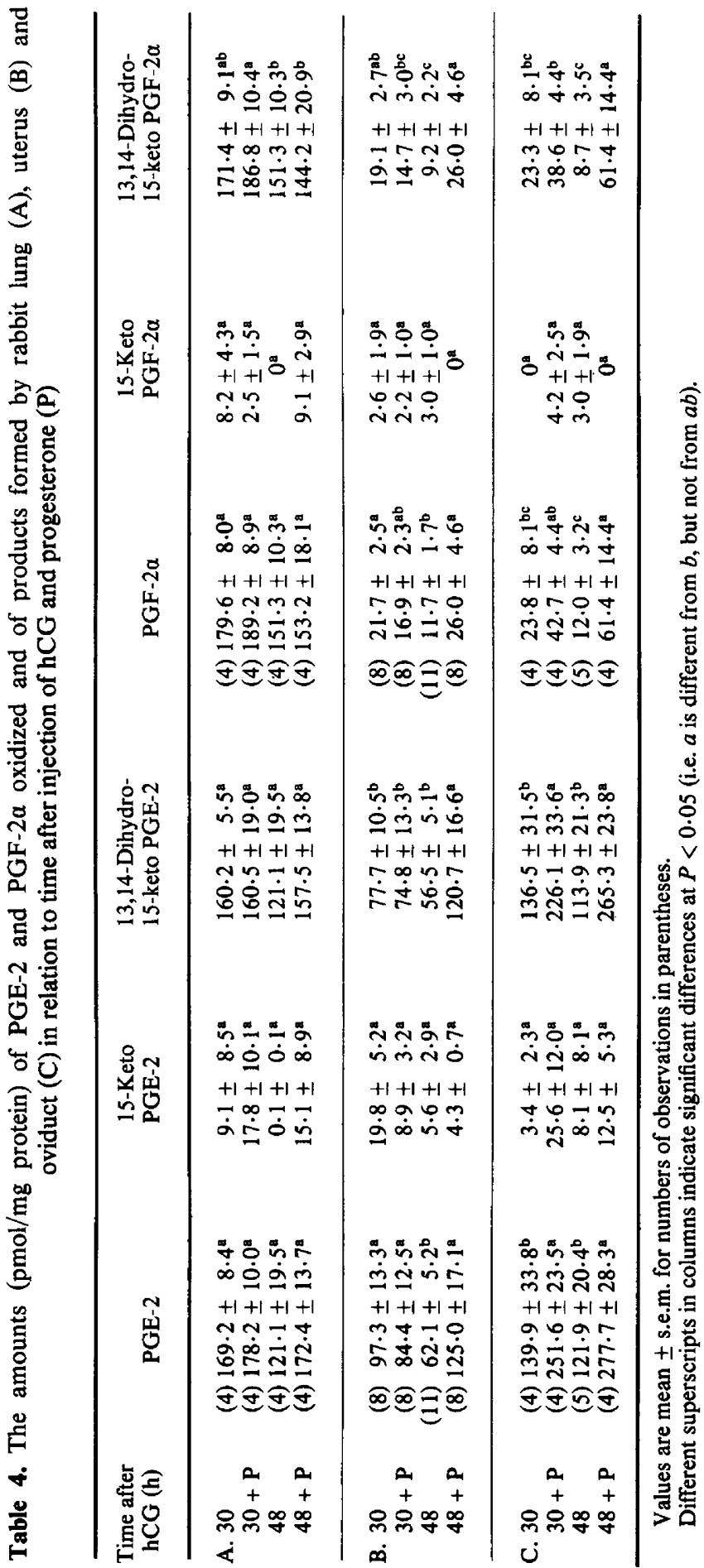


treatment. Oestrogen therefore altered only the ratio of products (in a variable manner) and not total production.

Treatment with progesterone before hCG produced the results shown in Table 4. In oviductal tissue, the metabolism of PGs was increased substantially above the level seen in oestrous animals, and the normal decline seen after hCG at 30 and $48 \mathrm{~h}$ was completely prevented. The decrease in PG metabolism that normally occurs in the uterus at $48 \mathrm{~h}$ after hCG was also prevented, but no significant increase over oestrous values was observed. Only in the oviduct and the $72 \mathrm{~h}$ uterus were differences between hormone-treated and untreated animals killed at the same time seen. Significantly more of both 13,14-dihydro-15-keto metabolites were formed at $48 \mathrm{~h}$ in the oviducts and at $72 \mathrm{~h}$ in the uterus; more 13,14-dihydro-15-keto PGE-2 was found at $30 \mathrm{~h}$ in the oviduct than in control animals.

\section{Discussion}

We had previously concluded that the activity of the prostaglandin synthetase system (cyclooxygenase) of the rabbit oviduct was not affected by the hormonal status of the animal (Valenzuela \& Harper, 1976). It therefore seemed likely that, if PGs were intimately concerned as one component of the regulatory mechanism of normal oviductal function, there would be changes in the ability of the oviduct to metabolize PGs. However, although there existed significant differences in the metabolism of PGE- 2 compared to PGF- $2 \alpha$ in the uterus and oviduct, there was no significant change in amount of metabolism in the oviduct with time after the ovulating injection for either PG. Study of percentage changes from oestrous values, however, indicated that there might be a change in ratio of metabolism of PGE-2, which would relax, to PGF-2 $\alpha$, which would contract, oviductal smooth muscle between 48 and $72 \mathrm{~h}$, times between which ova normally pass out of the oviduct into the uterus (Harper, Bennett, Boursnell \& Rowson, 1960) and progesterone levels have begun to rise (Spilman \& Wilks, 1976; Harrington \& Rothermel, 1977). At the same time a steady and significant decline in metabolism of PGE-2 and PGF-2 $\alpha$ by uterine tissue occurred, suggesting that we should have observed significant changes in metabolism by oviductal tissue if they existed. In animals treated with a dose of oestrogen at a time known to induce 'tube-locking' of ova (Chang \& Harper, 1966; Pauerstein, Sabry \& Hodgson, 1976), there was no change in the metabolism of PGE-2 or PGF$2 \alpha$ in the uterus or oviduct, although there was evidence for alteration in the ratio of PGE : PGF.

Progesterone treatment which causes accelerated transport of ova (Chang \& Bedford, 1961; Chang, 1966) did, however, significantly affect PG metabolism in the oviduct and in the uterus: in the oviduct metabolism of PGE-2 was increased by about 2, and that of PGF-2 $\alpha$ about 1.8 at $30 \mathrm{~h}$ and 5.0 at $48 \mathrm{~h}$. Since the oviductal cells could normally metabolize all of the PGE-2, but not all of the PGF-2 $\alpha$ produced, in the absence of active transport out of the cell (present study, and Valenzuela \& Harper, 1976), this increased metabolism would be expected to reduce the PGF dominant situation and thus permit relaxation of the isthmic musculature and passage of ova to the uterus.

The fact that increased 15-hydroxyprostaglandin dehydrogenase activity was found in the uterus and oviduct after progesterone treatment confirms the observations of Alam et al. (1976), except that these authors observed increased activity in both myometrium and deciduoma of rat uterus. In the present studies separate determinations on endometrium and myometrium were not made. Increased inactivation of PGE-2 by lung has also been recorded in pregnant and progesterone- or progesterone and oestradiol-treated rabbits, but not in those given oestradiol alone (Bedwani \& Marley, 1975), and in Day-18 pregnant rats (Blackwell \& Flower, 1976). In the present study increased inactivation of PGs by lung was not observed after progesterone, or after hCG injection. However, in the experiments of Bedwani \& Marley (1975) the rabbits had been exposed to long-term progesterone dominance (12 or more days of pregnancy or 12 or 
26 days treatment with $10 \mathrm{mg}$ progesterone $/ \mathrm{kg}$ ). Similarly, the studies of Alam et al. (1976) were on rats 7-11 days pseudopregnant, or 8 days pseudopregnant, ovariectomized and given one hormone injection and studied $24 \mathrm{~h}$ later (i.e. Day 9). These differences in amount and timing of hormone treatment between studies or the greater than optimal periods of incubation for lung in the present study may be responsible for the different results. Further serial studies will be required to resolve this question.

In the present studies we found that both uterus and oviduct metabolized PGE-2 significantly more rapidly than PGF-2 $\alpha$. Maule Walker \& Poyser (1978) have found essentially similar results in studies with Day 15 uteri of pregnant and non-pregnant guinea-pigs. Reproductive tissue clearly metabolizes PGs significantly more slowly than lung, reflecting the greater activity of the major metabolizing enzymes in the lung.

In conclusion, it seems that changes in activity of the reproductive tract for metabolism of PGs do occur and can be hormonally influenced. There is also some correlation with changes in metabolic activity and in the time of ovum transport through the oviduct following progesterone treatment.

We thank W. Friedrichs for technical assistance and Dr John Pike (Upjohn Co.) for the gift of prostaglandins. This work was supported in part by WHO contract S77121 and NIH grant P30HD10202 (Bioassay Core), and R.R.B. was a WHO Post-doctoral Fellow.

\section{References}

Alam, N.A., Russell, P.T., Tabor, M.W. \& Moulton, B.C. (1976) Progesterone and estrogen control of uterine dehydrogenase activity during deciduomal growth. Endocrinology 98, 859-863.

Bedwani, J.R. \& Marley, P.B. (1975) Enhanced inactivation of prostaglandin E-2 by the rabbit lung during pregnancy or progesterone treatment. $B r . J$. Pharmac, 53, 547-554.

Bito, L. (1975) Are prostaglandins intracellular, trans cellular or extracellular autocoids? Prostaglandins 9, $851-855$.

Blackwell, GJ. \& Flower, R.J. (1976) Effect of steroid hormones on tissue levels of prostaglandin 15hydroxydehydrogenase in the rat. Br. J. Pharmac. 56, 343P-344P.

Blackwell, G.J., Flower, R.J., Parsons, M.F. \& Vane, J.R. (1975a) Factors influencing prostaglandin turnover. Br.J. Pharmac. 53, 467P-468P.

Blackwell, G.J., Flower, R.J. \& Vane, J.R. (1975b) Rapid reduction of prostaglandin 15-hydroxydehydrogenase activity in rat tissues after treatment with protein synthesis inhibitors. Br.J. Pharmac. 55, 233-238.

Chang, M.C. (1966) Effects of oral administration of medroxyprogesterone acetate and ethinyl estradiol on the transportation and development of rabbit eggs. Endocrinology 79, 939-948.

Chang, M.C. \& Bedford, J.M. (1961) Effects of various hormones on the transportation of gametes and fertilization in the rabbit. Proc. 4th Int. Congr. Anim. Reprod. \& A.I., The Hague, pp. 367-370.

Chang, M.C. \& Harper, M.J.K. (1966) Effects of ethinyl estradiol on egg transport and development in the rabbit. Endocrinology 78, 860-872.

Ham, E.A., Cirillo, V.J., Zanetti, M.E. \& Kuehl, F., Jr (1975) Estrogen-directed synthesis of specific prostaglandins in uterus. Proc. natn. Acad. Sci., U.S.A. $72,1420-1424$.
Harper, M.J.K., Bennett, J.P., Boursnell, J.C. \& Rowson, L.E.A. (1960) An autoradiographic method for the study of egg transport in the rabbit Fallopian tube. $J$. Reprod. Fert. 1, 149-167.

Harper, M.J.K., Valenzuela, G. \& Hodgson, B.J. (1978) Accelerated ovum transport in rabbits induced by endotoxin 1. Changes in prostaglandin levels and reversal of endotoxin effect. Prostaglandins 15, 43-63.

Harrington, F.E. \& Rothermel, J.D. (1977) Daily changes in peripheral plasma progesterone concentrations in pregnant and pseudopregnant rabbits. Life Sci. 20, 1333-1340.

Hodgson, B.J., Harper, M.J.K. \& Valenzuela, G. (1978) Accelerated ovum transport in rabbits induced by endotoxin. 2. Changes in oviductal smooth muscle activity. Prostaglandins 15, 65-79.

Horton, E.W., Main, I.H.M. \& Marley, P.B. (1965) Effects of prostaglandins on the oviduct, studied in rabbits and ewes. J. Physiol., Lond. 180, 514-518.

Ingelman-Sundberg, A., Sandberg, F., Rydén, G. \& Molfese, A. (1971) The effect of prostaglandin $E_{1}$ on the circular and longitudinal musculature of the human oviduct in vitro. Acta obstet. gynec. scand. 50, Suppl. 9, p. 51.

Lowry, O.H., Rosebrough, N.J., Farr, A.L. \& Randall, R.J. (1951) Protein measurement with the folin phenol reagent. J. biol. Chem. 193, 265-275.

Maule Walker, F.M. \& Poyser, N.L. (1978) The metabolism of prostaglandins by the guinea-pig uterus with particular reference to corpus luteal maintenance in early pregnancy. Brit. J. Pharmac. 62, $177-183$.

Pauerstein, C.J., Sabry, A. \& Hodgson, B.J. (1976) Temporal relationships critical to estrogen-induced delay of ovum transport. Fert. Steril. 27, 1308-1311.

Samuelsson, B., Granstrom, E., Gréen, K., Hamberg, M. \& Hammarström, S. (1975) Prostaglandins. Ann. Rev. Biochem. 44, 669-695. 
Sokal, R.R. \& Rohlf, F.J. (1969) Biometry. W.H. Freeman \& Co., San Francisco.

Spilman, C.H. \& Harper, M.J.K. (1973) Effect of prostaglandins on oviduct motility in estrous rabbits. Biol. Reprod. 9, 36-45.

Spilman, C.H. \& Harper, M.J.K. (1974) Comparison of the effects of adrenergic drugs and prostaglandins on rabbit oviduct motility. Biol. Reprod. 10, 549554.

Spilman, C.H. \& Harper, M.J.K. (1975) Effect of prostaglandins on oviductal motility and egg transport. Gynec. Invest. 6, 186-205.

Spilman, C.H. \& Wilks, J.W. (1976) Peripheral plasma progesterone during egg transport in the rabbit. Proc. Soc. exp. Biol. Med. 151, 726-729.

Sun, F.F. \& Armour, S.B. (1974) Prostaglandin 15hydroxy-dehydrogenase and $\Delta^{13}$-reductase levels in the lungs of maternal, fetal and neonatal rabbits. Prostaglandins 7, 327-338.

Valenzuela, G. \& Harper, M.J.K. (1976) Effect of estrogen on activity of prostaglandin synthetase in rabbit oviduct. Prostaglandins 12, 535-549.

Zor, U., Strulovici, B., Nimrod, A. \& Lindner, H.R. (1977) Stimulation by cyclic nucleotides of prostaglandin $\mathbf{E}$ production in isolated Graafian follicles. Prostaglandins 14, 947-959.

Received 8 December 1978 